SHORT REPORT

\title{
Ethnic inequalities in campylobacter infection in Birmingham, UK: descriptive study of notified cases
}

\author{
S Manaseki, J Hawker, S Ali
}

J Epidemiol Community Health 2004;58:278-279. doi: 10.1136/jech.2003.012294

\begin{abstract}
Cod poisoning is the most commonly notified infection in - the UK and campylobacter is the most commonly identified microbial cause of those notifications. ${ }^{1}$ In Birmingham, a multiethnic city in England, there were 1209 statutory notifications with laboratory confirmation of Campylobacter $s p$ in 2001 and, unlike for salmonellosis, there is no evidence of any substantial decrease in cases in recent years. Despite this, the epidemiology of campylobacter infection is poorly understood. We analysed ethnic differences in notification rates by age in Birmingham in response to local observations.
\end{abstract}

\section{PARTICIPANTS, METHODS, AND RESULTS}

In Birmingham, all laboratory diagnosed cases of campylobacter infection are reported by laboratories to the "proper officer". All such symptomatic cases from 1987 to 1997 (inclusive) were analysed. The validated Nam Pechan computer program ${ }^{2}$ was used to attach ethnicity to surname and first name of the cases. Names were also visually checked by a South Asian researcher familiar with Muslim, Hindu, and Sikh names. Rates were obtained by averaging the number of infections per year by sex, age group, and ethnicity, and applying Birmingham 1991 census population data.

Altogether 9586 cases were identified (1384 Asian and 8202 non-Asian, a rate of $0.93 / 1000$ population per annum for Asians and 0.90/1000 for non-Asians). Figure l shows the pattern of infection rate by age group. Asians under 5 years in both sexes $(n=151)$ have over 2.5 times higher rates of infection than the non-Asians under $5(\mathrm{n}=562)$, (relative risk $(\mathrm{RR})=2.5,95 \%$ confidence intervals: 2.1 to 2.7 ). The 0-6 months olds in both groups had the highest numbers of infection (77 cases of Asians and 212 of non-Asians), but Asians had proportionally more infections compared with older age groups with a RR for under 6 month olds compared with older ages of 25.9 (18.9 to 35.63) for Asians and 1.19 ( 1.01 to 1.41 ) for non-Asians.

Conversely, non-elderly adults under 60 years of age were significantly at reduced risk in the Asians compared with the non-Asians (RR 15-16 years olds $=0.58(0.4$ to 0.7$)$ ). There was no significant ethnic difference in sex distribution, with more male than female cases in both groups. 33.2\% (32.2\% to $34.2 \%$ ) of non-Asian cases were notified in the period June to August, a statistically significantly higher proportion than in Asians (28.1\%; 25.7 to 30.5$)$.

\section{COMMENT}

Our results show that notification rates in young Asian children are more than twice those in non-Asians and a much higher proportion of cases in south Asians occur in infants. Although this result could be influenced by ethnic differences in health seeking behaviour, follow up of symptomatic family members by environmental health officers reduces the likelihood of this being the reason for the age distributions found within ethnic groups. It is important in such studies that the denominator population is reliable, but the use of incidence data from years either side of the 1991 census should have minimised the risk of outdated child denominators.

The bimodal age distribution for non-Asian cases is typical of that for developed countries. ${ }^{3}$ However, the distribution for Asian cases in Birmingham is more typical of developing countries, such as Bangladesh, where there are very high rates of infection in infants and no secondary peak in adults, because of immunity gained in childhood. ${ }^{4}$ Many older Asian adults in Birmingham will have been born abroad (97\% of $>29$ year olds were born abroad in 1991 census, although less than $55 \%$ of $20-29$ year olds). This pattern is consistent with increased exposure of Asian infants to campylobacter, which, if food related, could be attributable to differences in infant

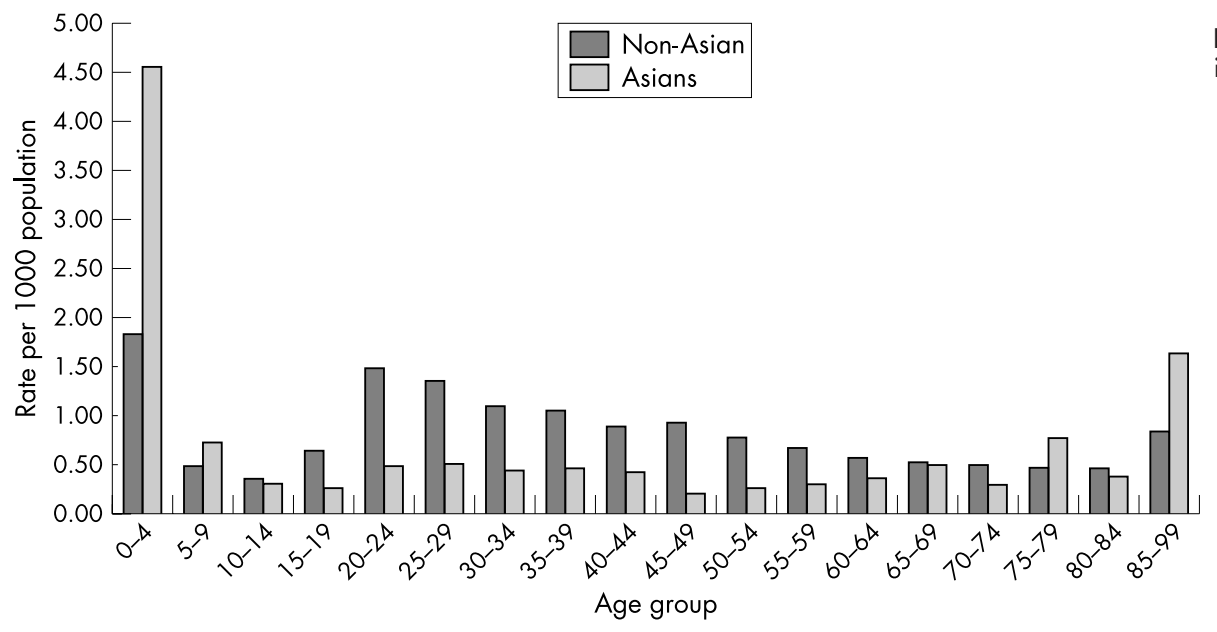

Figure 1 Mean annual campylobacter infection rate per 1000 population. 
feeding, different food providers, food preparation, or food hygiene practices. Travel to higher prevalence countries to visit relatives is common and could also contribute, as could person to person spread from non-toilet trained children. ${ }^{5}$ Finally, the possibility of differing susceptibilities to severe infection needs to be considered. Our findings should be tested on datasets held by other researchers and, if repeated, merit a case-control study to test potential risk factors.

\section{ACKNOWLEDGEMENTS}

We gratefully acknowledge the support of Jenny Millward and the Infection Control Unit at Birmingham City Council.

\section{Authors' affiliations}

S Manaseki, J Hawker, Department of Public Health and Epidemiology, University of Birmingham, Birmingham, UK

S Ali, South Birmingham Primary Care Trust, Kings Heath, Birmingham, UK

Funding: none.
Competing interests: none declared.

Correspondence to: Dr J Hawker, Department of Public Health and Epidemiology, University of Birmingham, Birmingham B15 2TT, UK; i.i.hawker@bham.ac.uk

Accepted for publication 19 August 2003

\section{REFERENCES}

1 Wheeler JG, Sethi D, Cowden JM. Study of infectious intestinal disease in England: rates in the community, presenting to general practice, and reported to national surveillance. BMJ 1999;318:1046-50.

2 Winter H, Cheng KK, Cummins C, et al. Cancer incidence in the South Asian Population of England (1990-92). Br J Cancer 1999;79:645-54.

3 Riley LW, Finch MJ. Results of the first year of national surveillance of Campylobacter infections in the United States. J Infect Dis 1985;151:956-9.

4 Taylor DN, Blaser MJ. Campylobacter infections. In: Bacterial infections of humans. Epidemiology and control. 2nd edn. New York: Plenum, 1991:151-72.

5 Oosterom J, Den Uyl CH, Banffer JR, et al. Epidemiological investigations on Campylobacter jejuni in households with a primary Infection. $J$ Hyg $1984 ; 93: 325-32$.

\section{THE JECH GALLERY}

\section{Is smallpox "in" again?}

7 a he World Health Assembly in 1980 endorsed the eradication of smallpox, as previously certified by a group of respected scientists in December 1979. ${ }^{1}$ The last case recorded of naturally occurring smallpox was in Somalia in 1977, although a laboratory accident in the United Kingdom in 1978 produced a fatal case that year. None the less, except for military stockpiles, the world was deemed to be free from the scourge.

Smallpox was causing around 10 million cases and 1.5-2 million deaths in the world every year in the mid-sixties, with costs estimated at US\$ 1000 million for developing countries and US\$ 350 millions for developed countries for 1967 alone. That same year the Intensified Smallpox Eradication Programme was started. Over the next decade, armed with a thermostable vaccine and mass vaccination and surveillance containment strategies, transmission of the disease was arrested. The overall cost of the eradication was estimated at US\$ 97 million for developed countries and about US\$200 million for the developing countries. After eradication was certified, on-going public health interventions to detect and control the disease ceased. Vaccination was stopped worldwide. The cost of vaccinating the US population alone just for 1967 had been $\$ 92.8$ million. As a result, savings have been immense. $^{2}$

The terrorist attacks of 11 September 2001 and others, have now placed smallpox back into the spotlight. Monkeypox ${ }^{3}$ (another of the orthopoxviruses) with similar clinical presentation in humans to that of smallpox has been sporadic in parts of Africa and responsible for disease outbreaks. ${ }^{4}$ Persons vaccinated against smallpox are protected against monkeypox.

This photograph was taken at a health centre office in Malawi in the mid-90s. At

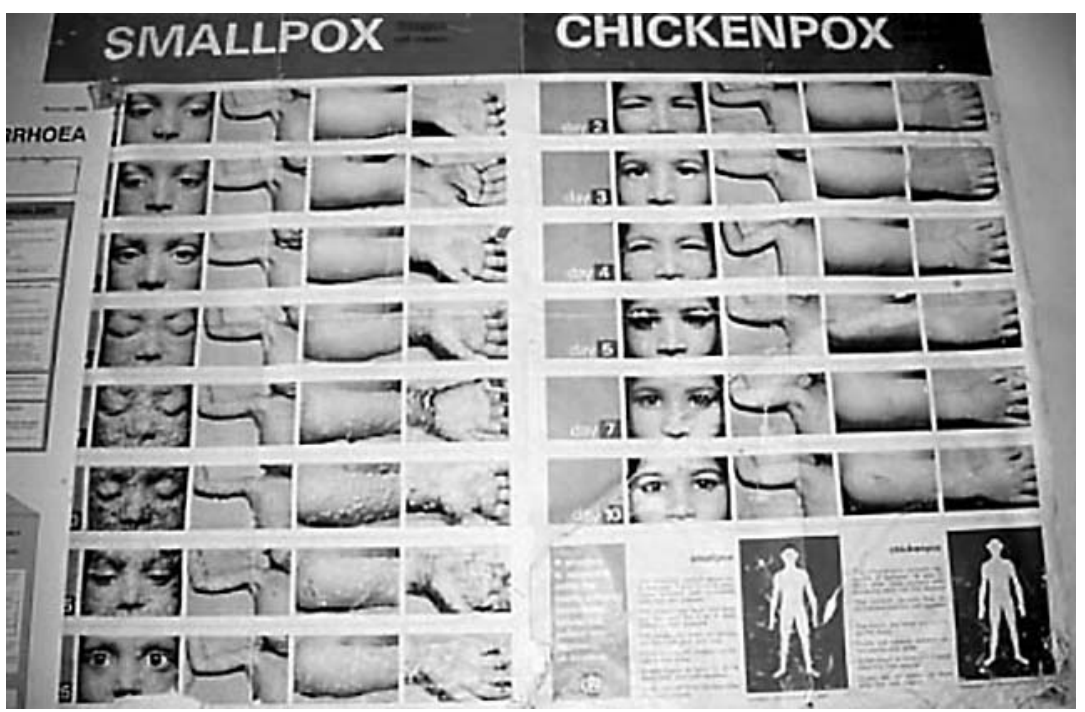

the time, it was like an odd curiosity, a relic of public health history but, unfortunately, smallpox has again become a matter of attention, study, and concern. ${ }^{6}$ Will it ever be necessary for the poster to be reprinted and distributed?

A M Torres Cantero

Departamento de Salud Pública, Historia de la Ciencia y Ginecología, Facultad de Medicina, Campus de Sant Joan 03550 San Juan de Alicante, Spain; atorres@umh.es

\section{REFERENCES}

1 World Health Organisation. http://www.who.int/emc/diseases/smallpox/factsheet.html

2 Fenner F, Henderson DA, Arita I, et al. Smallpox and its eradication. Geneva: World Health Organisation, 1988.

3 World Health Organisation. http://www.who.int/inf-fs/en/factl61.html

4 Centers for Disease Control and Prevention. http://www.cdc.gov/mmwr/preview/mmwrhtl/ $\mathrm{mm} 5227 \mathrm{a} 5 . \mathrm{htm}$

5 Henderson DA, Inglesby TV, Bartlett JG, et al. for the Working Group on Civilian Biodefense. Smallpox as a biological weapon. JAMA 1999;281:2127-37.

6 Centers for Disease Control and Prevention. http://www.bt.cdc.gov/agent/smallpox/basics/index.asp 